\title{
Complete resection of contrast-enhancing tumor volume is associated with improved survival in recurrent glioblastoma-results from the DIRECTOR trial
}

Suchorska, B ; Weller, M ; Tabatabai, G ; Senft, C ; Hau, P ; Sabel, M C ; Herrlinger, U ; Ketter, R ; Schlegel, U ; Marosi, C ; Reifenberger, G ; Wick, W ; Tonn, J C ; Wirsching, H G

\begin{abstract}
BACKGROUND The role of reoperation for recurrent glioblastoma (GBM) remains unclear. Prospective studies are lacking. Here, we studied the association of clinical outcome with extent of resection upon surgery for recurrent GBM in the patient cohort of DIRECTOR, a prospective randomized multicenter trial comparing 2 dose-intensified temozolomide regimens at recurrence of GBM. METHODS We analyzed prospectively collected clinical and imaging data from the DIRECTOR cohort $(\mathrm{N}=105)$. Volumetric analysis was performed on gadolinium contrast-enhanced MRI as well as fluid attenuated inversion recovery/T2 MRI and correlated with PFS after initial progression (PFS2) and post-recurrence survival (PRS). Quality of life was monitored by the EORTC QLQ-C30 and QLQ-BN20 questionnaires at 8-week intervals. RESULTS Seventy-one patients received surgery at first recurrence. Prognostic factors, including age, MGMT promoter methylation, and Karnofsky performance score, were balanced between patients with and without reoperation. Outcome in patients with versus without surgery at recurrence was similar for PFS2 (2.0 mo vs $1.9 \mathrm{mo}, \mathrm{P}=.360)$ and PRS (11.4 mo vs 9.8 mo, $\mathrm{P}=.633$ ). Among reoperated patients, post-surgery imaging was available in 59 cases. In these patients, complete resection of contrast-enhancing tumor $(\mathrm{N}=40)$ versus residual detection of contrast enhancement $(\mathrm{N}=$ 19) was associated with improved PRS (12.9 mo [95\% CI: 11.5-18.2] vs 6.5 mo [95\% CI: 3.6-9.9], P < .001 ) and better quality of life. Incomplete tumor resection was associated with inferior PRS compared with patients who did not undergo surgery (6.5 vs $9.8 \mathrm{mo}, \mathrm{P}=.052$ ). Quality of life was similar in these 2 groups. CONCLUSION Surgery at first recurrence of GBM improves outcome if complete resection of contrast-enhancing tumor is achieved.
\end{abstract}

DOI: https://doi.org/10.1093/neuonc/nov326

Posted at the Zurich Open Repository and Archive, University of Zurich

ZORA URL: https://doi.org/10.5167/uzh-124233

Journal Article

Accepted Version

Originally published at:

Suchorska, B; Weller, M; Tabatabai, G; Senft, C; Hau, P; Sabel, M C; Herrlinger, U; Ketter, R; Schlegel, U; Marosi, C; Reifenberger, G; Wick, W; Tonn, J C; Wirsching, H G (2016). Complete resection of contrast-enhancing tumor volume is associated with improved survival in recurrent glioblastoma-results from the DIRECTOR trial. Neuro-Oncology, 18(4):549-556.

DOI: https://doi.org/10.1093/neuonc/nov326 
Complete resection of contrast enhancing tumor volume is associated with improved survival in recurrent glioblastoma- results from the DIRECTOR trial

Bogdana Suchorska, $\mathrm{MD}^{1}$, Michael Weller, $\mathrm{MD}^{2}$, Ghazaleh Tabatabai, MD, $\mathrm{PhD}^{2,3}$, Christian Senft, $M D^{4}$, Peter Hau, $M D^{5}$, Michael C. Sabel, $M^{6}{ }^{6}$, Ulrich Herrlinger, $M^{7}$, Ralf Ketter, $M D^{8}$, Uwe Schlegel, MD ${ }^{9}$, Christine Marosi, $\mathrm{MD}^{10}$, Guido Reifenberger, $\mathrm{MD}^{11}$, Wolfgang Wick, $M D^{12}$, Jörg C. Tonn, $M D^{1}$, Hans-Georg Wirsching, $M D^{2}$

${ }^{1}$ Dept. of Neurosurgery, Ludwig-Maximilians University Munich Marchioninistr. 15, 81377, Munich, Germany; ${ }^{2}$ Dept. of Neurology, University Hospital Zurich, Frauenklinikstrasse 26, 8091, Zurich, Switzerland; ${ }^{3}$ Dept. of Neurology, University Hospital Tuebingen, Hoppe-Seyler Str.3, 72076, Tuebingen, Germany; ${ }^{4}$ Dept. of Neurosurgery, University Hospital Frankfurt am Main, Schleusenweg 2-16, 60528 Germany; ${ }^{5}$ Dept. of Neurology, University Hospital Regensburg, Franz-Josef-Strauß-Allee 11, 93053, Regensburg, Germany; ${ }^{6}$ Dept. of Neurosurgery, University Hospital Duesseldorf, Moorenstr. 5, 40225, Düsseldorf, Germany; 'Dept. of Neurology, University Hospital Bonn, Sigmund-Freud-Str, 25, 53127, Bonn, Germany; ${ }^{8}$ Dept. of Neurosurgery, University Hospital Saarland, Kirrberger Str., 66424, Homburg/Saar, Germany; ${ }^{9}$ Dept. of Neurology, Knappschaftskrankenhaus Bochum, In der Schornau 23, 44892, Bochum Germany; ${ }^{10}$ Dept. of Oncology, Vienna General Hospital, Währinger Gürtel 18-20, 1090, Vienna, Austria; ${ }^{11}$ Institute of Neuropathology, University Hospital Duesseldorf, Moorenstr. 5, 40225, Düsseldorf, Germany; ${ }^{12}$ Dept. of Neurology, University Hospital Heidelberg, Im Neuenheimer Feld 400, 69120, Heidelberg, Germany

Corresponding author:

Dr. Bogdana Suchorska

Department of Neurosurgery

Ludwig-Maximilians-University Munich

Marchioninistr. 15

81377 Munich, Germany

Phone: +4989440072893

Fax: +4989440075894

Mail: bogdana.suchorska@med.uni-muenchen.de 
Word count: 4376 (including tables) Tables: 3, Figures: 2. Supplemetary Data: 7 Tables.

Funding:

The DIRECTOR trial (NCT 00941460) was supported by a grant from MSD (formerly

Schering Plough) and a Matching Funds grant from the University Hospital Zurich,

Switzerland

Conflict of Interest:

B. Suchorska reports no disclosures. M. Weller is an advisory board member for MSD and reports receiving research grants from MSD. G. Tabatabai reports receiving a travel grant from MSD. Ch. Senft reports no disclosures. P. Hau reports no disclosures. M.C. Sabel reports no disclosures. U. Herrlinger reports receiving speakers bureau honoraria from Medac. R. Ketter reports no disclosures. U. Schlegel is a consultant/advisory board member for Roche and reports receiving speakers bureau honoraria from GlaxoSmithKline and Medac.C. Marosi reports no disclosures. G. Reifenberger reports receiving commercial research grants from Roche and speakers bureau honoraria from Amgen and Roche. W. Wick reports receiving speakers bureau honoraria from Roche, MSD and Prime Oncology. J-C. Tonn is a consultant/advisory board member for Merck Serono and Roche and reports receiving speakers bureau honoraria from Merck Serono and Roche. H.-G. Wirsching reports no disclosures. 


\section{Abstract}

Background: The role of reoperation for recurrent GBM remains unclear. Prospective studies are lacking. Here, we studied the association of clinical outcome with extent of resection upon surgery for recurrent GBM in the patient cohort of DIRECTOR, a prospective randomized multicenter trial comparing two doseintensified temozolomide (TMZ) regimens at recurrence of GBM.

Methods: We analyzed prospectively collected clinical and imaging data from the DIRECTOR cohort $(\mathrm{N}=105)$. Volumetric analysis was performed on gadolinium (CE)enhanced as well as FLAIR/T2 MRI and correlated with progression-free survival after initial progression $\left(\mathrm{PFS}_{2}\right)$ and post recurrence-survival (PRS). Quality of life (QoL) was monitored by EORTC QLQ-C30 and QLQ-BN20 in 8-weekly intervals.

Results: Seventy-one patients received surgery at first recurrence. Prognostic factors, including age, MGMT promoter methylation and Karnofsky performance score were balanced between patients with and without reoperation. Outcome in patients with versus without surgery at recurrence was similar for $\mathrm{PFS}_{2}$ (2.0 months versus 1.9 months, $p=0.360$ ) and PRS (11.4 months versus 9.8 months, $p=0.633$ ). Among re-operated patients, post-surgery imaging was available in 59 cases. In these patients, complete resection of CE-enhancing tumor $(\mathrm{N}=40)$ versus residual detection of CE enhancement $(\mathrm{N}=19)$ was associated with improved PRS (12.9 months [95\% $\mathrm{Cl} 11.5-18.2]$ versus 6.5 months [95\% $\mathrm{Cl} 3.6-9.9], \mathrm{p}<0.001)$ and better QoL. Incomplete tumor resection was associated with inferior PRS compared to patients who did not undergo surgery (6.5 versus 9.8 months, $p=0.052$ ). QoL was similar in these two groups.

Conclusions: Surgery at first recurrence of GBM improves outcome if complete resection of CE-enhancing tumor is achieved. 
Key words: recurrent GBM, DIRECTOR, re-operation, volumetry, outcome

\section{Introduction}

Standard of care in GBM consists of gross total resection whenever feasible followed by involved field irradiation (RT) with concomitant temozolomide (TMZ) chemotherapy and subsequent 6 cycles of maintenance TMZ ${ }^{1}$. Since introduction of this standard ${ }^{2}$, overall survival has increased to approximately 16 months in clinical trials, with superior outcome of 25-30 months in patients with MGMT promoter methylation ${ }^{3-5}$. Microsurgical tumor resection as initial treatment contributes to prolonged overall survival, if complete resection of contrast enhancing tumor (CRET) is achieved ${ }^{6-9}$. While CRET is considered to be the gold-standard whenever safely feasible at the time of initial diagnosis, its value at recurrence is still subject to debate $^{10}$. The skepticism about the value of surgical resection in recurrent GBM may be due to the poor prognosis of patients with recurrent $\mathrm{GBM}^{11}$, a rather high incidence of surgical morbidity following reoperation ${ }^{12}$ and the general debate on the value of microsurgical reduction of tumor burden in malignant glioma. The recently published prospective randomized multicenter DIRECTOR trial evaluated the efficacy and tolerability of two different regimens of temozolomide (TMZ) at first progression after adjuvant chemoradiotherapy $(\mathrm{TMZ} / \mathrm{RT} \rightarrow \mathrm{TMZ})^{13}$. Major inclusion criteria were progressive or recurrent GBM as documented with MRI no earlier than 180 days after first surgery and no earlier than 90 days after end of RT. Furthermore, information about MGMT methylation status and completion of concomitant RT/TMZ plus at least 2 cycles of maintenance TMZ were required. Patients with and without reoperation were included. A Karnofsky performance score (KPS) of $\geq 50$ was mandatory for inclusion. All patients received either regimen of a dose intensified TMZ re-challenge 
- both arms showed similar outcome. Thus, this data set provides a well-annotated patient cohort to analyze the association of extent of resection (EOR) on the basis of MRI volumetry with outcome in the framework of a well-controlled post-recurrence treatment setting.

\section{Methods}

\section{Study design}

GBM patients enrolled in the DIRECTOR trial were analyzed for associations of surgery and EOR at first progression with outcome. Indication for surgery was commonly based on recommendations from multidisciplinary tumor boards. Outcome measures were time to next progression (PFS 2 , as opposed to the time of diagnosis to first progression, $\mathrm{PFS}{ }_{1}$ ) and post recurrence survival (PRS). $\mathrm{PFS}_{2}$ was defined as the duration from the date of first study drug administration until further progression. PRS was defined as the duration from the date of the first study drug administration to the date of tumor related death.

Disease status was monitored by MRI in 8-weekly intervals and assessed using Macdonald criteria ${ }^{14}$. At the time of data analysis (April 17, 2015), tumor progression had been documented in 99 patients, and death in 95 of all 105 patients, all tumorrelated. Three patients were lost to follow-up before tumor progression. The DIRECTOR study was approved by the local ethical committees; all patients gave written informed consent prior to inclusion.

\section{Neuroimaging studies}


Imaging data available from the original DIRECTOR trial was retrospectively analyzed for the present study while all remaining data was based on prospective analyses. Post-surgical MRI was performed within 72 hours following surgery.

Volumetric analyses of pre- and postsurgical MR images were performed by an experienced investigator (B.S.) blinded to patients' outcome. Manual segmentation of pre- and postsurgical contrast-enhanced (CE-) T1 and T2/FLAIR images was performed using the pencil-drawing tool of the Osirix Software, Version 3.6.1 (Internetfreeware). Volume calculation of (CE-) T1 and T2/FLAIR tumor portion was performed by multiplying the sum of tumor areas outlined on each transverse slice by the corresponding slice thickness ${ }^{15}$. In case of blood remnants along the borders of the resection cavity, pre-contrast $\mathrm{T} 1$ volume was subtracted from the (CE-) T1 volume.

Concerning the (CE-) T1 image sequences, we obtained both: volumes with necrotic or cystic areas including enhancing parts as well as volumes with solid enhancing parts only. Resection cavities resulting from surgery were not included, neither in the (CE-) T1 nor in the T2/FLAIR volume calculation.

In the surgery cohort, which did not include biopsies, CRET was defined as absence of any contrast enhancing tumor volume on (CE-) T1 imaging, while incomplete resection refers to patients with remnant CE-enhancing tumor after surgical procedure.

In addition, an analysis considering the functional relevance (motor/supplementary motor cortex, primary somatosensitive area, Broca and Wernicke area) of the affected brain area was performed: tumor location was classified as "eloquent" versus "non-eloquent" accordingly ${ }^{16}$. 


\section{Quality of life}

Quality of life (QoL) was monitored by EORTC quality of life questionnaire (QLQ)C30 and QLQ-BN20 in 8-weekly intervals ${ }^{13}$. The QLQ-C30 incorporates five functional scales: general physical symptoms, physical functioning, psychological distress, social functioning, and fatigue/malaise. The BN20 is a module developed in particular for patients with brain cancer and comprises four domain scores (future uncertainty, visual disorder, motor dysfunction, communication deficit) and seven symptom items (headache, seizures, drowsiness, hair loss, itching, difficulty with bladder control and weakness of the legs) ${ }^{17,18}$.

\section{Statistical methods}

The Chi-square test was used to compare categorical variables and the Wilcoxon test was applied to compare continuous variables. Events in survival models were defined as radiographic tumor progression for $\mathrm{PFS}_{2}$ and as death of any cause for PRS. The log-rank and bootstrap tests were used to compare median times and rates at fixed time points. Receiver operating characteristics (ROC) analysis was performed to establish MRI-based volume thresholds. Associations of surgery, EOR and ROC-derived tumor volume thresholds with outcome were analyzed in a Cox proportional hazards model. Age, KPS, MGMT promoter methylation, and steroid intake were included in this Cox model. Mann-Whitney-U-test was performed for QoL data analysis, as the data were largely not normally distributed. 


\section{Results}

\section{Patient characteristics}

Of 105 patients enrolled, 71 patients underwent surgery prior to study entry (Figure 1). Characteristics of patients who underwent surgery for recurrent disease versus patients who did not undergo surgery are summarized in Table 1. MGMT promoter methylation, first-line treatment, progression-free survival from first diagnosis following first-line treatment $\left(\mathrm{PFS}_{1}\right)$ as well as KPS and steroid intake at study entry were balanced between both groups.

Tumor volumes at recurrence were similar in patients who did or did not undergo surgery, but post-operative tumor volumes at study entry were smaller in the surgical cohort than in patients that did not undergo surgery. Radiographic CRET was achieved in 40 of 59 assessable patients (67.8\%) who underwent surgery. Among patients who underwent surgery, MGMT promoter methylation, first-line treatment, $\mathrm{PFS}_{1}$, as well as KPS and steroid intake at study entry were balanced between patients with CRET versus incomplete resection. Preoperative tumor volumes at recurrence were larger in patients with incomplete resection $(p=0.004)$, tumors with incomplete resection were more often localized in eloquent regions $(p=0.178)$, (Table S1). One patient developed a post-operative wound infection within the first month after surgery and required discontinuation of TMZ, but no other severe complications from tumor resection were documented.

\section{Outcome by surgery}

Clinical outcome parameters were comparable in patients who underwent surgery versus patients who did not undergo surgery for recurrent disease prior to study entry (Figure 2A,B, Table S2). PRS was 11.4 months $(95 \% \mathrm{Cl}, 8.4-12.3)$ in patients who 
underwent surgery versus 9.8 months $(95 \% \mathrm{Cl}, 6.6-15.1)$ in patients who did not undergo surgery $(\mathrm{p}=0.633)$.

Next we explored a prognostic role for EOR. Among patients who underwent surgery at recurrence, PRS was longer in patients with CRET (12.9 months [95\% Cl, 11.5 18.2]) than in patients with incomplete tumor resection (6.5 months [95\% $\mathrm{Cl}, 3.6-9.9])$ $(p<0.001)$ (Figure 2C,D, Table 2). Incomplete tumor resection was even associated with a trend to inferior PRS compared to patients who did not undergo surgery $(6.5$ versus 9.8 months, $\mathrm{p}=0.052$ ) (Figure $2 \mathrm{E}, \mathrm{F}$, Table S3). Comparing outcome between no surgery and CRET in the univariate analysis, there was an advantage for CRET as far as $\mathrm{PFS}_{2}$ is concerned: 1.87 (Cl95\%: 1.84-1.9) months vs. 3.5 (Cl95\%: 1.8-5.2) months, log-rank $p=0.05$. The difference was pronounced, however, not statistically significant for PRS: 9.6 (CI95\% 6.2-12.9) months vs. 13.2 (CI95\% 9.1-17.3) months, log-rank $p=0.087$. Multivariate analysis revealed CRET to be prognostic for PRS ( $p$ $=0.05$ ) besides MGMT and KPS (please also see Table S7). Volumetric analysis across the entire study population of volumes prior to study entry revealed (CE-) T1 volumes with as well as (CE-) T1 without necrosis to be highly associated ( $p$ $<0.0001)$ with longer $\mathrm{PFS}_{2}$ and PRS.

Of note, tumor volumes at study entry were similar in patients who underwent incomplete tumor resection (median $4.0 \mathrm{~cm}^{3}$ [range: $1.1-25.3$ ]) versus patients who did not undergo surgery (median $5.1 \mathrm{~cm}^{3}$ [range: 1.0-25.2]) $(p=0.635)$. Tumor location regarding eloquent brain regions was not significant for outcome (11.08 months [95\% Cl, 9.3-12.9] vs. 11.5 months [95\% Cl, 5.2-17.8]).

Finally, we analyzed the outcome of all patients with contrast-enhancing tumor at study entry (e.g. patients without surgery and those with an incomplete resection) versus patients with $\mathrm{CRET}$ (Figure2G,H, Table S4). Detection of contrast-enhancing tumor was associated with shorter $\mathrm{PFS}_{2}(p=0.025)$ and PRS $(p=0.007)$. ROC 
analysis using the median PRS (10.5 months) for determining the volume threshold for discrimination between inferior and superior post-recurrence survival was performed: concerning the postoperative (CE-) $\mathrm{T} 1$ with and without necrosis as well as T2/FLAIR volumes, a threshold could not be determined due to the large number of cases with complete resection.

\section{Multivariate modeling of post-operative outcome}

We applied a Cox proportional hazards model to identify prognostic factors after surgery. Univariate analyses of the association of factors that were included in this Cox model with outcome are summarized in Table S5. CRET was prognostic for PRS on multivariate analysis, in contrast to age, MGMT promoter methylation status, KPS or steroid intake, at study entry (Table 3). Gender or study arm were also not prognostic when tested in this model as additional single variables (data not shown). CRET was not prognostic for PRS when Cox proportional hazards modeling was applied to $\mathrm{PFS}_{2}(\mathrm{p}=0.061)$. When CRET was replaced surgery "yes vs no" in the same Cox model, only MGMT promoter methylation status was prognostic for OS (Table S6) and $\mathrm{PFS}_{2}(\mathrm{p}=0.003)$ in the log-rank test.

\section{Quality of life}

Regarding the entire group at the first follow up after 8 weeks, patients who received surgery had higher cognitive functioning values $(p=0.046)$. Constipation was also more common in this group $(p=0.039)$. Patients who underwent an incomplete resection were more likely to suffer from general motor dysfunction $(p=0.04)$ and to have a worse global health status $(p=0.008)$ compared to those who underwent CRET. 


\section{Discussion}

In contrast to the existing standard of care in primary GBM, treatment of GBM progression after standard of care treatment remains poorly defined and is increasingly individualized, taking into considerations prior treatment, time of relapse, pattern of tumor spread at relapse as well as increasingly molecular marker profiles $1,11,19$. Surgery with complete resection of solid, contrast-enhancing tumor has been shown to be associated with improved survival in newly diagnosed $\mathrm{GBM}^{7,8,20-22}$. However, only a minority of patients is considered eligible for second surgery - KPS, tumor volume and eloquent tumor location have recently been identified as selection criteria for patients to benefit from reoperation ${ }^{23,24}$. Only $13-30 \%$ of all recurrent GBM patients are considered as candidates for a second surgery ${ }^{25}$.

Yet, the evidence for these recommendations is low and commonly based on retrospective case series. The DIRECTOR trial explored tolerability and efficacy of two different regiments of dose-intensified TMZ in patients with GBM at first progression $^{13}$. Since this trial cohort is clinically well annotated and both TMZ treatment arms had identical outcomes, it provides an excellent opportunity to explore the association of surgery at recurrence with outcome. The majority $(68 \%)$ of patients had surgery for recurrent disease prior to being enrolled in this trial. This number is considerably higher than in previous reports on re-operation in recurrent GBM (13-30\%), however, the present data are based on a multicenter trial enrolling patients from 10 large neurosurgical centers ${ }^{25,26}$. As reported in the primary report of the DIRECTOR trial, patients with versus without surgical intervention prior to study enrolment had a similar outcome ${ }^{13}$. Recently, in a cohort study from a prospective registry in Italy with 764 patients over a period of 14 years no survival benefit was detected for reoperation, similar to an analysis done by the North American Brain 
Tumor Consortium (NABTC) on 758 patients being enrolled over 11 years ${ }^{25-27}$. However, all three reports did not consider the volumetric EOR but merely whether patients had undergone second surgery at all. In addition, reports in which extent of re-resection was considered were neither controlled for additional therapies nor were data prospectively collected according to a protocol.

Here we categorized the surgical intervention at recurrence in a simple binary mode: after reoperation 40 patients had no residual tumor determined by volumetry of contrast-enhanced MRI whereas 19 patients did. A comparison of these two cohorts demonstrated that extent of resection was prognostic for outcome. Further sensitivity analyses demonstrated that the presence versus absence of residual tumor at study entry remained prognostic irrespective of surgery. In fact, incomplete resection showed even a trend to inferior outcome compared to no resection at all prior to study entry. Of note, it has to be assumed that some patients undergoing second surgery in this setting had postoperative morbidity that prevented them from being eligible for the DIRECTOR trial according to the inclusion criteria. Hence, the cohort of this study has undergone selection by omitting patients with severe postoperative complications and the present analysis can focus more specifically on the role of resection itself. In addition, the uniform treatment of all patients with dose-intensified TMZ re-challenge provides a much more homogeneous cohort to analyze the role of extent of resection since the spectrum of additional therapy after re-resection was heterogeneous in previous studies.

A recent literature review performed by use of the PubMed and Ovid Medline databases for 1980 through 2013 revealed only 31 studies with data from single or multiple institutions. Twenty-nine proposed a survival benefit or improved functional status after reoperation for recurrent high-grade glioma ${ }^{10}$. This was confirmed in a recent study analyzing 503 patients ${ }^{28}$. However, selection criteria for and influence of 
additional post re-resection therapy remained unclear. Even more, the role of incomplete re-resection is yet vague since no comparison with matched cohorts of non-re-resected patients had been performed. More aggressive resection bears the risk of increased surgical morbidity and has been found to be doubled once volumetric resection of more than $80 \%$ was achieved ${ }^{12}$. The influence of procedurerelated morbidity on timing and intensity of additional antitumor treatment after reresection had never been analyzed although one might assume that patients with surgical complications might be withheld from intensified oncological therapy in the context of recurrent GBM. These confounding factors do not interfere in our study because of inclusion criteria and treatment design of the DIRECTOR trial which led to a very homogeneous cohort.

Here we report that only those patients experience prolonged survival in whom a complete resection of the solid contrast-enhancing tumor mass was accomplished. Quality of life regarding cognitive and neurological function was superior in this cohort compared to patients with measurable disease on MRI after reoperation. Compared to the non-resected cohort, incomplete resection did not result in better outcome, neither regarding survival nor quality of life. Indeed, PRS was shorter by trend in patients with residual tumor after reoperation despite similar tumor volumes. These considerations allow to conclude that surgery for recurrent GBM should only be considered if CRET can be safely achieved.

Future studies dealing with post-recurrence treatment have to analyze whether the study arms are balanced for CRET. Clark et al concluded from their NABTC analysis that data from patients with and without reoperation might be combined for the assessment of new treatment options since PFS-6 and OS were similar in both cohorts. However, the simple discrimination solely between surgery yes/no revealed 
no difference in the past in contrast to our study and former reports adjusting for extent of re-resection ${ }^{12,13,25,26,29}$.

Our study has inherent limitations. Although the data were collected prospectively, it is still a retrospective, exploratory analysis that was not pre-specified. Furthermore, it still remains a possibility that patients with tumors that were amenable to CRET were per se tumors with a better prognosis due to a different biology, e.g. being less invasive. A randomized trial to prospectively assess the role of complete resection at GBM progression has recently started (NCT 02394626).

\section{Conclusion}

According to the data of this well controlled study population surgery at first recurrence of GBM improves outcome both in terms of survival and quality of life only if complete resection of CE-enhancing tumor is safely achieved.

\section{REFERENCES}

1. Weller M, van den Bent $\mathrm{M}$, Hopkins $\mathrm{K}$, et al. EANO guideline for the diagnosis and treatment of anaplastic gliomas and glioblastoma. Lancet Oncol. 2014; 15(9):e395403.

2. Stupp R, Mason WP, van den Bent MJ, et al. Radiotherapy plus concomitant and adjuvant temozolomide for glioblastoma. The New England journal of medicine. 2005; 352(10):987-996.

3. Gilbert MR, Dignam JJ, Armstrong TS, et al. A randomized trial of bevacizumab for newly diagnosed glioblastoma. The New England journal of medicine. 2014; 370(8):699-708.

4. Stupp R, Hegi ME, Gorlia T, et al. Cilengitide combined with standard treatment for patients with newly diagnosed glioblastoma with methylated MGMT promoter 
(CENTRIC EORTC 26071-22072 study): a multicentre, randomised, open-label, phase 3 trial. Lancet Oncol. 2014; 15(10):1100-1108.

5. Chinot OL, Wick W, Mason W, et al. Bevacizumab plus radiotherapy-temozolomide for newly diagnosed glioblastoma. The New England journal of medicine. 2014; 370(8):709-722.

6. Stummer W, Reulen HJ, Meinel T, et al. Extent of resection and survival in glioblastoma multiforme: identification of and adjustment for bias. Neurosurgery. 2008; 62(3):564-576; discussion 564-576.

7. Sanai N, Polley MY, McDermott MW, Parsa AT, Berger MS. An extent of resection threshold for newly diagnosed glioblastomas. Journal of neurosurgery. 2011; 115(1):3-8.

8. Kreth FW, Thon N, Simon M, et al. Gross total but not incomplete resection of glioblastoma prolongs survival in the era of radiochemotherapy. Annals of oncology: official journal of the European Society for Medical Oncology / ESMO. 2013; 24(12):3117-3123.

9. Stummer W, Pichlmeier U, Meinel T, et al. Fluorescence-guided surgery with 5aminolevulinic acid for resection of malignant glioma: a randomised controlled multicentre phase III trial. Lancet Oncol. 2006; 7(5):392-401.

10. Hervey-Jumper SL, Berger MS. Reoperation for recurrent high-grade glioma: a current perspective of the literature. Neurosurgery. 2014; 75(5):491-499; discussion 498-499.

11. Weller M, Cloughesy T, Perry JR, Wick W. Standards of care for treatment of recurrent glioblastoma--are we there yet? Neuro-oncology. 2013; 15(1):4-27.

12. Oppenlander ME, Wolf AB, Snyder LA, et al. An extent of resection threshold for recurrent glioblastoma and its risk for neurological morbidity. Journal of neurosurgery. 2014; 120(4):846-853.

13. Weller M, Tabatabai G, Kastner B, et al. MGMT Promoter Methylation Is a Strong Prognostic Biomarker for Benefit from Dose-Intensified Temozolomide Rechallenge in Progressive Glioblastoma: The DIRECTOR Trial. Clinical cancer research : an official journal of the American Association for Cancer Research. 2015; 21(9):20572064.

14. Macdonald DR, Cascino TL, Schold SC, Jr., Cairncross JG. Response criteria for phase II studies of supratentorial malignant glioma. Journal of clinical oncology : official journal of the American Society of Clinical Oncology. 1990; 8(7):1277-1280. 
15. Suchorska B, Jansen NL, Linn J, et al. Biological tumor volume in 18FET-PET before radiochemotherapy correlates with survival in GBM. Neurology. 2015; 84(7):710-719.

16. Passingham RE, Stephan KE, Kotter R. The anatomical basis of functional localization in the cortex. Nature reviews. Neuroscience. 2002; 3(8):606-616.

17. Efficace F, Bottomley A. Health related quality of life assessment methodology and reported outcomes in randomised controlled trials of primary brain cancer patients. Eur J Cancer. 2002; 38(14):1824-1831.

18. Taphoorn MJ, Claassens L, Aaronson NK, et al. An international validation study of the EORTC brain cancer module (EORTC QLQ-BN20) for assessing health-related quality of life and symptoms in brain cancer patients. Eur J Cancer. 2010; 46(6):10331040.

19. Niyazi M, Siefert A, Schwarz SB, et al. Therapeutic options for recurrent malignant glioma. Radiotherapy and oncology : journal of the European Society for Therapeutic Radiology and Oncology. 2011; 98(1):1-14.

20. Lacroix M, Abi-Said D, Fourney DR, et al. A multivariate analysis of 416 patients with glioblastoma multiforme: prognosis, extent of resection, and survival. Journal of neurosurgery. 2001; 95(2):190-198.

21. Grabowski MM, Recinos PF, Nowacki AS, et al. Residual tumor volume versus extent of resection: predictors of survival after surgery for glioblastoma. Journal of neurosurgery. 2014; 121(5):1115-1123.

22. Chaichana KL, Jusue-Torres I, Navarro-Ramirez R, et al. Establishing percent resection and residual volume thresholds affecting survival and recurrence for patients with newly diagnosed intracranial glioblastoma. Neuro-oncology. 2014; 16(1):113122.

23. Park CK, Kim JH, Nam DH, et al. A practical scoring system to determine whether to proceed with surgical resection in recurrent glioblastoma. Neuro-oncology. 2013; 15(8):1096-1101.

24. Park JK, Hodges T, Arko L, et al. Scale to predict survival after surgery for recurrent glioblastoma multiforme. Journal of clinical oncology : official journal of the American Society of Clinical Oncology. 2010; 28(24):3838-3843.

25. Nava F, Tramacere I, Fittipaldo A, et al. Survival effect of first- and second-line treatments for patients with primary glioblastoma: a cohort study from a prospective registry, 1997-2010. Neuro-oncology. 2014; 16(5):719-727. 
26. Clarke JL, Ennis MM, Yung WK, et al. Is surgery at progression a prognostic marker for improved 6-month progression-free survival or overall survival for patients with recurrent glioblastoma? Neuro-oncology. 2011; 13(10):1118-1124.

27. Gorlia T, Stupp R, Brandes AA, et al. New prognostic factors and calculators for outcome prediction in patients with recurrent glioblastoma: a pooled analysis of EORTC Brain Tumour Group phase I and II clinical trials. European journal of cancer. 2012; 48(8):1176-1184.

28. Ringel F, Pape H, Sabel M, et al. Clinical benefit from resection of recurrent glioblastomas: results of a multicenter study including 503 patients with recurrent glioblastomas undergoing surgical resection. Neuro-oncology. 2015.

29. Bloch $\mathrm{O}$, Han SJ, Cha S, et al. Impact of extent of resection for recurrent glioblastoma on overall survival: clinical article. Journal of neurosurgery. 2012; 117(6):1032-1038. 


\section{Figure legends}

Figure 1. Consort Chart. Surgery and extent of resection prior to study entry in the DIRECTOR trial. Arm A [one week on (120 mg/m(2) per day)/one week off temozolomide]; Arm B [3 weeks on $(80 \mathrm{mg} / \mathrm{m}$ (2) per day)/one week off temozolomide]. Black: patients who did not undergo surgery; White: patients with CRET (complete resection of contrast-enhancing tumor); light grey: patients with incomplete resection

Figure 2. Outcome by surgery and residual disease on the baseline MRI. PFS 2 (time to next progression) (A) and PRS (B) in all patients who underwent surgery for recurrent disease $(\mathrm{N}=71)$ versus patients who did not undergo surgery $(\mathrm{N}=34)$. $\mathrm{PFS}_{2}$ (C) and PRS (D) in patients who underwent surgery for recurrent disease prior to study entry with residual disease $(N=19)$ versus CRET $(N=40)$ on the baseline MRI. $\mathrm{PFS}_{2}(\mathrm{E})$ and $\mathrm{PRS}(\mathrm{F})$ in patients with incomplete tumor resection $(\mathrm{N}=19)$ versus patients who did not undergo surgery $(\mathrm{N}=34)$. $\mathrm{PFS}_{2}(\mathrm{G})$ and PRS $(\mathrm{H})$ in patients with radiographically detectable disease on the baseline $M R I(N=53)$ versus patients with CRET $(\mathrm{N}=40)$. 
Table 1. Patient characteristics prior to enrolment.

\begin{tabular}{|c|c|c|c|}
\hline & \multicolumn{2}{|c|}{ Surgery for recurrence } & \multirow[b]{2}{*}{$\mathrm{p}$} \\
\hline & $\begin{array}{l}\text { Yes } \\
N=71\end{array}$ & $\begin{array}{c}\text { No } \\
\mathrm{N}=34\end{array}$ & \\
\hline \multicolumn{4}{|l|}{ Age at diagnosis } \\
\hline Median (years) & 55 & 59.5 & \multirow{2}{*}{0.495} \\
\hline Range (years) & $25-77$ & $21-72$ & \\
\hline \multicolumn{4}{|l|}{ Gender: N (\%) } \\
\hline Male & $48(67.6)$ & $21(61.8)$ & \multirow{2}{*}{0.555} \\
\hline Female & $23(32.4)$ & $13(38.2)$ & \\
\hline \multicolumn{4}{|l|}{ MGMT promoter: $\mathbf{N}(\%)$} \\
\hline Methylated & $31(43.7)$ & $15(44.1)$ & \multirow{2}{*}{0.965} \\
\hline Unmethylated & $40(56.3)$ & $19(55.9)$ & \\
\hline \multicolumn{4}{|l|}{ First-line therapy: } \\
\hline Number of maintenance TMZ cycles & & & \\
\hline Median & 6.0 & 6.0 & \multirow{2}{*}{0.444} \\
\hline Range & $2-12$ & $2-12$ & \\
\hline Time to first progression (months) & & & \\
\hline
\end{tabular}




\begin{tabular}{|c|c|c|c|}
\hline Median & 11.5 & 10.7 & 0.366 \\
\hline Range & $3.9-80.9$ & $5.4-50.0$ & \\
\hline \multicolumn{4}{|c|}{ Tumor volume at recurrence $\left(\mathrm{cm}^{3}\right)$} \\
\hline Median & 9.5 & 5.1 & \multirow{2}{*}{0.234} \\
\hline Range & $0.2-71.4$ & $1.0-23.2$ & \\
\hline \multicolumn{4}{|c|}{ Tumor volume at study entry $\left(\mathrm{cm}^{3}\right)$} \\
\hline Median & 0.3 & 5.1 & \multirow{2}{*}{$<0.001$} \\
\hline Range & $0-25.0$ & $1.0-23.2$ & \\
\hline \multicolumn{4}{|c|}{ KPS at study entry: $\mathrm{N}(\%)$} \\
\hline $90-100$ & $40(56.3)$ & $20(58.8)$ & \multirow{3}{*}{0.880} \\
\hline $70-80$ & $22(31.0)$ & $9(26.5)$ & \\
\hline$<70$ & $9(12.7)$ & $5(14.7)$ & \\
\hline \multicolumn{4}{|c|}{ Steroids at study entry: N (\%) } \\
\hline Yes & $20(31.3)$ & $8(28.6)$ & \multirow{2}{*}{0.797} \\
\hline No & $44(68.7)$ & $20(71.4)$ & \\
\hline \multicolumn{4}{|c|}{ Study arm: N (\%) } \\
\hline $\operatorname{Arm~A}$ & $34(47.9)$ & $18(52.9)$ & \multirow{2}{*}{0.628} \\
\hline Arm B & $37(52.1)$ & $16(47.1)$ & \\
\hline
\end{tabular}


*Considers only patients with available imaging data; MGMT: 06-methylguanine-DNA-methyltransferase thylguanine-DNA-methyltransferase TMZ: temozolomide; KPS: Karnofsky Performance Score 
Table 2. Outcome by extent of resection.

\begin{tabular}{|c|c|c|c|c|c|c|c|}
\hline & \multicolumn{6}{|c|}{ Extent of resection } & \\
\hline & \multicolumn{3}{|c|}{ GTR } & \multicolumn{3}{|c|}{ Incomplete } & \\
\hline & Patients & Events & $\begin{array}{l}\text { Time in } \\
\text { months } \\
(95 \% \mathrm{Cl})\end{array}$ & Patients & Events & $\begin{array}{l}\text { Time in } \\
\text { months } \\
(95 \% \mathrm{Cl})\end{array}$ & $\mathrm{p}$ \\
\hline Median $\mathrm{PFS}_{2}$ & 40 & 37 & $3.5[2.0-5.1]$ & 19 & 19 & $1.9[1.3-3.5]$ & 0.016 \\
\hline Median PRS & 40 & 34 & $\begin{array}{c}12.9 \\
{[11.5-18.2]}\end{array}$ & 19 & 18 & 6.5 [3.6-9.9] & $<0.001$ \\
\hline & & & $\begin{array}{l}\text { Rate in \% } \\
(95 \% \mathrm{Cl})\end{array}$ & & & $\begin{array}{l}\text { Rate in\% } \\
(95 \% \mathrm{Cl})\end{array}$ & \\
\hline $\mathrm{PFS}_{2}$ at 6 months & 39 & 29 & 25.6 & 18 & 16 & 11.1 & 0.063 \\
\hline
\end{tabular}




\begin{tabular}{|l|c|c|c|c|c|c|}
\hline & & & {$[11.3-40.0]$} & & {$[5.0-27.2]$} & \\
\hline Survival rate at 12 & 39 & 16 & 59.0 & 18 & 15 & 16.7 \\
months from first & & & {$[42.8-75.1]$} & & {$[2.4-35.7]$} & \\
study drug & & & & & & \\
administration & & & & & & \\
\hline
\end{tabular}

GTR: gross total resection; $\mathrm{PFS}_{2}$ : time to next progression; PRS: post-recurrence survival; Cl: confidence interval 
Table S1. Patient characteristics by extent of resection.

\begin{tabular}{|c|c|c|c|}
\hline & \multicolumn{2}{|c|}{ Extent of resection } & \multirow[b]{2}{*}{$\mathrm{p}$} \\
\hline & $\begin{array}{l}\text { GTR } \\
\mathrm{N}=40\end{array}$ & $\begin{array}{l}\text { Incomplete } \\
\qquad N=19\end{array}$ & \\
\hline \multicolumn{4}{|l|}{ Age at diagnosis } \\
\hline Median (years) & 56.5 & 55 & \multirow{2}{*}{0.773} \\
\hline Range (years) & $25-77$ & $39-76$ & \\
\hline \multicolumn{4}{|l|}{ Gender: $\mathbf{N}(\%)$} \\
\hline Male & $25(62.5)$ & $16(84.2)$ & \multirow{2}{*}{0.091} \\
\hline Female & $15(37.5)$ & $3(15.8)$ & \\
\hline \multicolumn{4}{|c|}{ MGMT promoter: $\mathbf{N}(\%)$} \\
\hline Methylated & $20(50.0)$ & $7(36.8)$ & \multirow{2}{*}{0.343} \\
\hline Unmethylated & $20(50.0)$ & $12(63.2)$ & \\
\hline \multicolumn{4}{|c|}{$\begin{array}{l}\text { First-line therapy: } \\
\text { Number of maintenance } \mathrm{TMZ} \text { cycles }\end{array}$} \\
\hline Median & 6.0 & 6.0 & \multirow{2}{*}{0.875} \\
\hline Range & $2-12$ & $2-12$ & \\
\hline \multicolumn{4}{|c|}{ Time to first progression (months) } \\
\hline Median & 12.0 & 10.6 & \multirow{2}{*}{0.897} \\
\hline Range & $3.9-80.9$ & $7.0-51.9$ & \\
\hline \multicolumn{4}{|c|}{ Tumor volume at recurrence $\left(\mathrm{cm}^{3}\right)$} \\
\hline Median & 6.9 & 21.5 & \multirow{2}{*}{0.004} \\
\hline Range & $0.2-58.2$ & $1.2-71.4$ & \\
\hline
\end{tabular}




\begin{tabular}{|c|c|c|c|}
\hline Tumor ve & & & \\
\hline Median & 0 & 4.0 & \multirow{2}{*}{ N.A. } \\
\hline Range & N.A. & $1.1-25.3$ & \\
\hline \multicolumn{4}{|c|}{ KPS at study entry: $\mathrm{N}(\%)$} \\
\hline $90-100$ & $26(65.0)$ & $8(42.1)$ & \multirow{3}{*}{0.235} \\
\hline $70-80$ & $11(27.5)$ & $8(42.1)$ & \\
\hline$<70$ & $3(7.5)$ & $3(15.8)$ & \\
\hline \multicolumn{4}{|c|}{ Steroids at study entry: N (\%) } \\
\hline Yes & $15(40.5)$ & $3(18.8)$ & \multirow{2}{*}{0.206} \\
\hline No & $22(59.5)$ & $13(81.2)$ & \\
\hline \multicolumn{4}{|c|}{ Study arm: N (\%) } \\
\hline $\operatorname{Arm~A}$ & $22(55.0)$ & $9(47.4)$ & \multirow{2}{*}{0.583} \\
\hline Arm B & $18(45.0)$ & $10(52.6)$ & \\
\hline \multicolumn{4}{|c|}{ Eloquent location } \\
\hline Yes & 28 & 16 & \multirow{2}{*}{0.187} \\
\hline No & 12 & 3 & \\
\hline
\end{tabular}


Table S2. Outcome by surgery for recurrence.

\begin{tabular}{|c|c|c|c|c|c|c|c|}
\hline & \multicolumn{6}{|c|}{ Surgery for recurrence } & \\
\hline & \multicolumn{3}{|c|}{ Yes } & \multicolumn{3}{|c|}{ No } & \\
\hline & Patients & Events & $\begin{array}{l}\text { Time in } \\
\text { months } \\
(95 \% \mathrm{Cl})\end{array}$ & Patients & Events & $\begin{array}{l}\text { Time in } \\
\text { months } \\
(95 \% \mathrm{Cl})\end{array}$ & $p$ \\
\hline Median $\mathrm{PFS}_{2}$ & 71 & 68 & $2.0[1.9-3.7]$ & 34 & 31 & $1.9[1.8-2.0]$ & 0.360 \\
\hline Median PRS & 71 & 64 & $\begin{array}{c}11.4 \\
{[8.4-12.3]}\end{array}$ & 34 & 31 & $\begin{array}{c}9.8 \\
{[6.6-15.1]}\end{array}$ & 0.633 \\
\hline & & & $\begin{array}{l}\text { Rate in \% } \\
(95 \% \mathrm{Cl})\end{array}$ & & & $\begin{array}{l}\text { Rate in\% } \\
(95 \% \mathrm{Cl})\end{array}$ & \\
\hline $\mathrm{PFS}_{2}$ at 6 months & 69 & 54 & $\begin{array}{c}21.7 \\
{[11.8-31.8]}\end{array}$ & 33 & 27 & $\begin{array}{c}18.2 \\
{[4.3-32.1]}\end{array}$ & 0.230 \\
\hline Survival rate at & 69 & 40 & 42.0 & 33 & 19 & 42.4 & 0.885 \\
\hline
\end{tabular}




\begin{tabular}{|l|l|l|l|l|l|l|}
\hline $\begin{array}{l}12 \text { months from } \\
\text { first study drug }\end{array}$ & & {$[30.1-54.0]$} & & & {$[24.6-60.2]$} & \\
administration & & & & & & \\
\hline
\end{tabular}


Table S3. Outcome by surgery for recurrence in patients with radiographically detectable disease.

\begin{tabular}{|c|c|c|c|c|c|c|c|}
\hline & \multicolumn{6}{|c|}{ Surgery for recurrence } & \\
\hline & \multicolumn{3}{|c|}{ Yes } & \multicolumn{3}{|c|}{ No } & \\
\hline & Patients & Events & $\begin{array}{l}\text { Time in } \\
\text { months } \\
(95 \% \mathrm{Cl})\end{array}$ & Patients & Events & $\begin{array}{l}\text { Time in } \\
\text { months } \\
(95 \% \mathrm{Cl})\end{array}$ & $p$ \\
\hline Median $\mathrm{PFS}_{2}$ & 19 & 19 & $1.9[1.3-3.4]$ & 34 & 31 & $1.9[1.8-2.0]$ & 0.405 \\
\hline $\begin{array}{l}\text { Median PRS from } \\
\text { first study drug } \\
\text { administration }\end{array}$ & 19 & 18 & $6.5[3.6-9.9]$ & 34 & 31 & $9.8[6.6-15.1]$ & 0.052 \\
\hline & & & $\begin{array}{l}\text { Rate in\% } \\
(95 \% \mathrm{Cl})\end{array}$ & & & $\begin{array}{l}\text { Rate in\% } \\
(95 \% \mathrm{Cl})\end{array}$ & \\
\hline $\mathrm{PFS}_{2}$ at 6 months & 18 & 16 & 11.1 & 33 & 27 & 18.2 & 0.760 \\
\hline
\end{tabular}




\begin{tabular}{|l|c|c|c|c|c|c|}
\hline & & & {$[5.0-27.2]$} & & {$[4.3-32.1]$} & \\
\hline Survival rate at 12 & 18 & 15 & 16.7 & 33 & 19 & 42.4 \\
months from first & & & {$[2.4-35.7]$} & & & 0.063 \\
study drug & & & & & & \\
administration & & & & & & \\
\hline
\end{tabular}


Table S4. Outcome by radiographically detectable disease on the baseline MRI at study entry.

\begin{tabular}{|c|c|c|c|c|c|c|c|}
\hline & \multicolumn{6}{|c|}{ Radiographically detectable disease } & \multirow[b]{3}{*}{$\mathrm{p}$} \\
\hline & \multicolumn{3}{|c|}{ Yes } & \multicolumn{3}{|c|}{ No } & \\
\hline & Patients & Events & $\begin{array}{c}\text { Time in months } \\
(95 \% \mathrm{Cl})\end{array}$ & Patients & Events & $\begin{array}{c}\text { Time in months } \\
(95 \% \mathrm{Cl})\end{array}$ & \\
\hline Median $\mathrm{PFS}_{2}$ & 53 & 50 & 1.9 [1.8-1-9] & 40 & 37 & $3.5[2.0-4.4]$ & 0.025 \\
\hline $\begin{array}{l}\text { Median PRS from first } \\
\text { study drug } \\
\text { administration }\end{array}$ & 53 & 49 & $9.2[6.5-11.4]$ & 40 & 34 & $\begin{array}{c}12.9 \\
{[11.7-18.7]}\end{array}$ & 0.007 \\
\hline & & & $\begin{array}{l}\text { Rate in\% } \\
(95 \% \mathrm{Cl})\end{array}$ & & & $\begin{array}{l}\text { Rate in \% } \\
(95 \% \mathrm{Cl})\end{array}$ & \\
\hline $\mathrm{PFS}_{2}$ at 6 months & 51 & 43 & $\begin{array}{c}15.7 \\
{[5.4-26.0]}\end{array}$ & 39 & 29 & $\begin{array}{c}25.6 \\
{[11.3-40.0]}\end{array}$ & 0.035 \\
\hline
\end{tabular}




\begin{tabular}{|l|c|c|c|c|c|c|}
\hline Survival rate at 12 & 51 & 34 & 33.3 & 39 & 0.005 \\
months from first study & & & {$[19.9-46.7]$} & & & \\
drug administration & & & & & & \\
\hline
\end{tabular}



Table S5. Univariate analyses of associations with inferior survival.

\begin{tabular}{|l|c|c|}
\hline & Hazard ratio and & $\mathbf{p}$ \\
\hline Extent of resection: GTR versus incomplete & $0.35(0.19-0.64)$ & 0.001 \\
\hline Age at study entry: 18-54 versus 55+ years & $1.10(0.73-1.66)$ & 0.647 \\
\hline MGMT promoter: methylated versus unmethylated & $0.45(0.29-0.68)$ & $<0.001$ \\
\hline KPS at study entry: 90-100\% versus KPS 50-80\% & $0.71(0.47-1.01)$ & 0.099 \\
\hline Steroids at study entry: no versus yes & $1.21(0.76-1.94)$ & 0.427 \\
\hline
\end{tabular}


Table S6. Multivariate analyses of predictors of inferior survival. ${ }^{a}$

\begin{tabular}{|l|c|c|}
\hline & Hazard ratio and & $\mathbf{p}$ \\
\hline Surgery at recurrence & $0.73(0.45-1.20)$ & 0.213 \\
\hline Age at study entry: $18-54$ versus 55+ years & $1.04(0.65-1.66)$ & 0.870 \\
\hline MGMT promoter: methylated versus unmethylated & $0.38(0.23-0.63)$ & $<0.001$ \\
\hline KPS at study entry: 90-100\% versus KPS 50-80\% & $0.64(0.40-1.03)$ & 0.067 \\
\hline Steroids at study entry: no versus yes & $0.85(0.51-1.40)$ & 0.512 \\
\hline
\end{tabular}

${ }^{\text {a }}$ Patients with complete clinical and imaging data $(\mathrm{N}=91)$. 
Table S7. Multivariate analyses of predictors of inferior outcome regarding GTR/no surgery ${ }^{a}$.

\begin{tabular}{|l|c|c|}
\hline PRS & Hazard ratio and & $\mathbf{p}$ \\
\hline GTR versus no surgery & $0.57(0.32-0.99)$ & 0.05 \\
\hline Age at study entry: $18-54$ versus 55+ years & $0.87(0.49-1.54)$ & 0.63 \\
\hline MGMT promoter: methylated versus unmethylated & $0.30(0.16-0.55)$ & $<0.0001$ \\
\hline KPS at study entry: $90-100 \%$ versus KPS 50-80\% & $0.5(0.28-0.90)$ & 0.02 \\
\hline Steroids at study entry: no versus yes & $0.82(0.37-1.20)$ & 0.18 \\
\hline PFS ${ }_{2}$ & Hazard ratio and & p \\
\hline Steroids at study entry: no versus yes & $95 \%$ cl & \\
\hline GTR versus no surgery & $0.69(0.39-1.20)$ & 0.18 \\
\hline Age at study entry: $18-54$ versus 55+ years & $0.66(0.35-1.24)$ & 0.20 \\
\hline MGMT promoter: methylated versus unmethylated & $0.55(0.31-0.97)$ & 0.04 \\
\hline
\end{tabular}


${ }^{\mathrm{a}}$ Patients with complete clinical and imaging data. GTR: gross total resection; MGMT: O6-methylguanineDNA-methyltransferase thylguanine-DNA-methyltransferase; KPS: Karnofsky Performance Score 

Figure 2

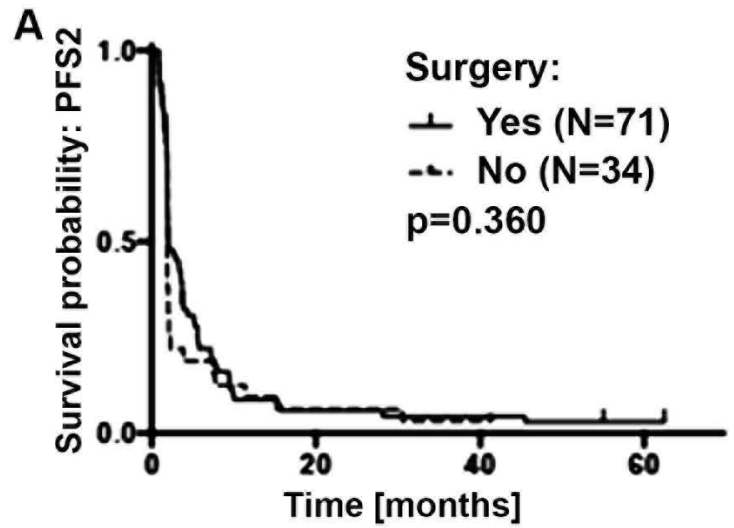

B
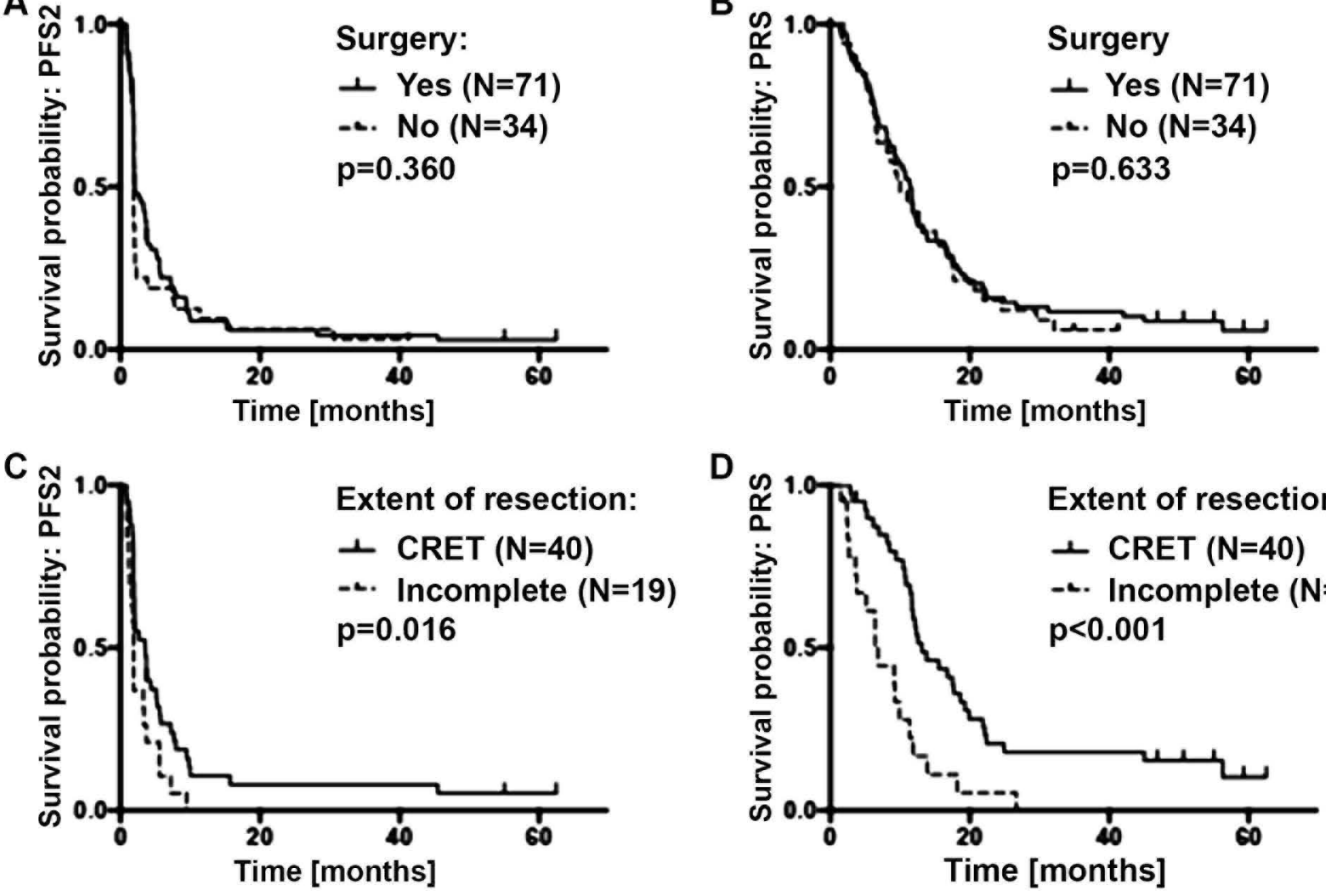

E

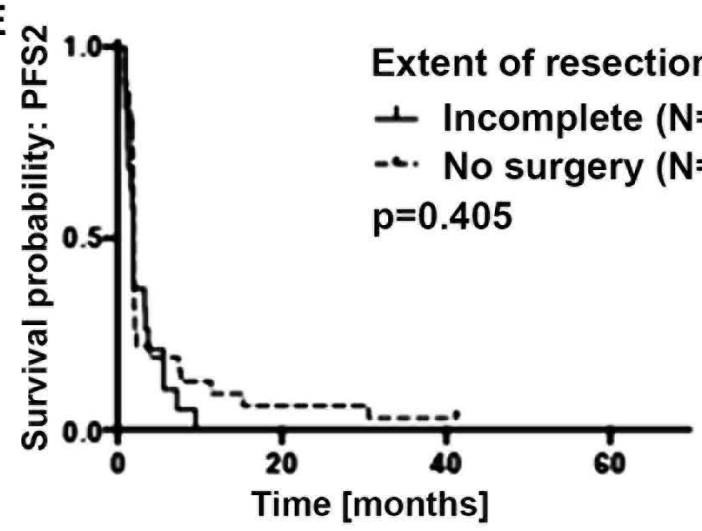

G

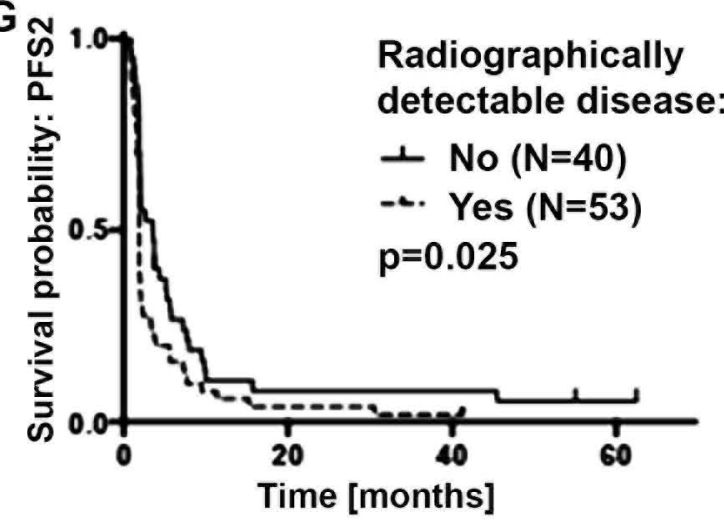

D

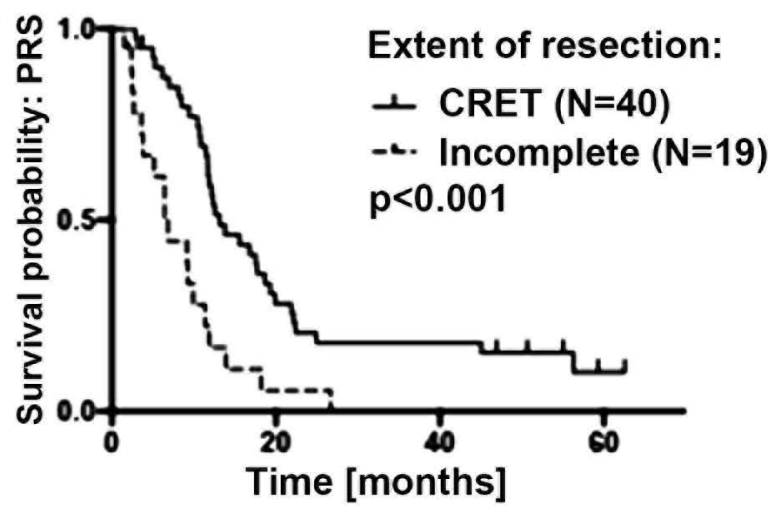

F

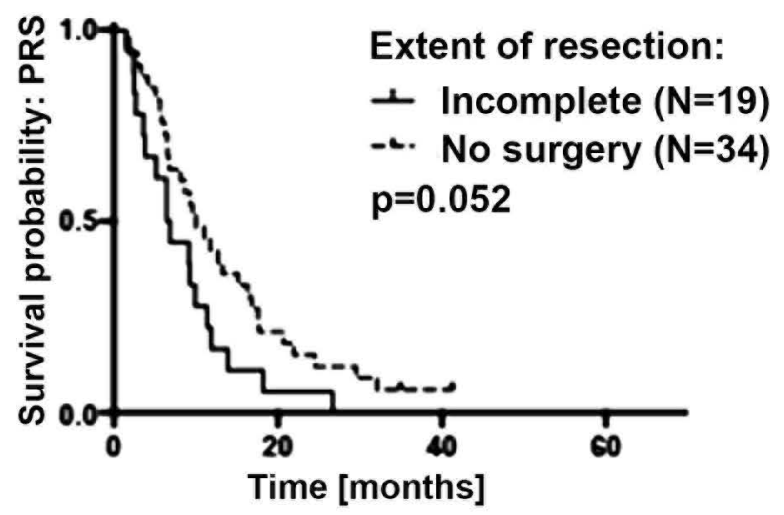

H

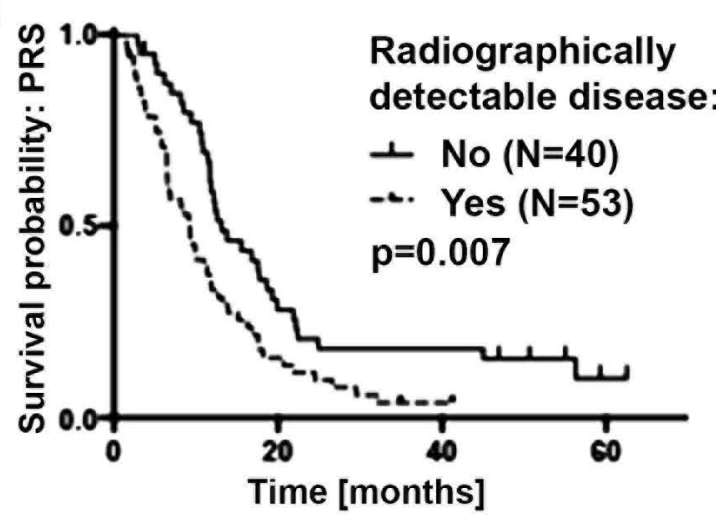

